\title{
Nature of Exchange Rates Cyclicality in Central and Eastern European Countries
}

\author{
Daniel Stavárek
}

\begin{abstract}
This paper provides empirical evidence on relationship between cyclical components of real effective exchange rate (REER) and selected macroeconomic fundamentals that are frequently used in exchange rate determination models. The analysis focuses on ten Central and Eastern European countries over the period 1998-2011. Cross correlation is applied on quarterly, filtered and seasonally adjusted data. Correlation coefficients are usually sufficiently high if REER leads or lags the respective variable of more than two quarters. However, results on procyclicality, acyclicality or countercyclicality of exchange rates are ambiguous and differ across the analyzed countries. Level of the country's openness does not significantly affect intensity of the relationship between REER and macroeconomic fundamentals.
\end{abstract}

Index Terms-Business cycle, cross correlation, exchange rate, macroeconomic fundamentals.

\section{INTRODUCTION}

The question of relationship between exchange rates and economic fundamentals has been one of the most intensively examined issues in international economics since the collapse of the Bretton Woods system [1]. Numerous theoretical as well as empirical models suppose that exchange rates are determined by various macroeconomic variables and can be applied for prediction of future exchange rate development. As an illustration, we can use monetary class of models. Although each model that belongs to this family introduces some specific attributes we are able to derive a conventional set of fundamentals that is shared by the entire group of monetary models of exchange rate determination [2]. This set of fundamentals consists of money supply, gross domestic product or income, long-term interest rate, inflation rate and trade balance.

However, as documented by e.g. [3], this relationship is not evident in data and the respective models often fail empirically. Missing relationship between exchange rates and macroeconomic aggregates is labeled as "exchange rate disconnect puzzle" and is one of the six major puzzles in international economics overviewed by [4]. There is also evidence that business cycle properties of macroeconomic aggregates are only slightly affected by the exchange rate regime applied [5].

The aim of the paper is to identify a nature of relationship between exchange rates and selected macroeconomic

Manuscript received April 23, 2013; revised June 30, 2013. This work was supported by the Czech Science Foundation within the project GAČR 403/11/2073 "Procyclicality of financial markets, asset price bubbles and macroprudential regulation". This support is gratefully acknowledged.

D. Stavárek is with the Silesian University in Opava, School of Business Administration in Karviná, Czech Republic (e-mail: stavarek@ opf.slu.cz). fundamentals in ten countries from Central and Eastern Europe - members of the European Union. In empirical estimation, we respect the business cycle and cyclical properties of the included variables to enhance credibility of results. It is also crucial to emphasize what is not aimed in the paper. Even though we are inspired by monetary models in selection of macroeconomic aggregates we neither evaluate their relevance in exchange rate determination nor attempt to predict exchange rate development.

\section{DATA AND Methodology USED}

The empirical estimation is performed for ten countries, namely Bulgaria (BG), Czech Republic (CZ), Estonia (EE), Hungary (HU), Latvia (LV), Lithuania (LT), Poland (PL), Romania (RO), Slovakia (SK), and Slovenia (SI). The dataset used in the analysis consists of quarterly data on gross domestic product (GDP), long-term interest rate represented by 10-year government bond yield, money supply, trade balance expressed as a ratio of exports on imports and real effective exchange rate (REER). All time series covers the period of 1998:1 - 2011:4. Earlier observations were excluded from the dataset due to data inconsistency stemming from turbulent and extraordinary economic development in some of the countries.

The only source of data is the Eurostat Economy and Finance online database. The time series are generally in local currencies, constant prices and seasonally adjusted. The REER series are constructed for 27 main trading partners. An increase of the exchange rate represents a real appreciation of the domestic currency against a basket of other currencies contained in the basket. We use REER for three reasons. First, effective exchange rates capture the role of exchange rates from the macroeconomic point of view more reliably than bilateral exchange rates. Second, REER by itself reflects the effect of inflation differential and, hence, inflation may not be included in the set of macroeconomic variables. Third, three countries (BG, LT, LV) were applying currency board or similar kind of exchange rate arrangement during the entire period of analysis. Moreover, EE substituted currency board with membership in the euro area on January 1, 2011. Two more countries (SI, SK) adopted the euro even earlier. Hence, nominal effective exchange rate would be hard to interpret.

Before the analysis, all time series were converted into logs. Then, we use the Hodrick-Prescott filter (HP filter) to obtain a cyclical component of each time series. Next, we run cross correlations to all combinations of changes in cyclical component of REER and macroeconomic fundamental.

The HP filter has been widely used in economic literature 
to estimate an unobservable time trend for time series variables. Let $y_{t}$ denote an observable macroeconomic time series. The HP filter decomposes into $y_{t}$ a nonstationary trend $g_{t}$ and a stationary residual cyclical component $c_{t}$ that is:

$$
y_{t}=g_{t}+c_{t}
$$

Note that $g_{t}$ and $c_{t}$ are unobservables. Since $c_{t}$ is a stationary process we can think of $y_{t}$ as a noisy signal for the nonstationary trend $g_{t}$. Hence, the problem boils down to how extract an estimate for $g_{t}$ from data on $y_{t}$. Given an adequately chosen, positive value of $\lambda$, there is a trend component that will minimize:

$$
\min _{\left\{g_{t}\right\}_{t=1}^{T}} \sum_{t=1}^{T}\left(y_{t}-g_{t}\right)^{2}+\lambda \sum_{t=2}^{T-1}\left[\left(g_{t+1}-g_{t}\right)-\left(g_{t}-g_{t-1}\right)\right]^{2}
$$

The first term of the equation is the sum of the squared deviations which penalizes the cyclical component. The second term is a multiple $\lambda$ of the sum of the squares of the trend component's second differences. This second term penalizes variations in the growth rate of the trend component. The larger the value of $\lambda$, the higher is the penalty. Hodrick and Prescott advise that, for quarterly data, a value of $\lambda=1600$ is reasonable.

Cross correlation assesses how one reference time series correlates with another time series, or several other series, as a function of time shift (lag). Cross correlation does not yield a single correlation coefficient but rather a whole series of correlation values. Like all correlations, cross correlation only shows statistical associations not causation. Consider two financial series $x_{t}$ and $y_{t}$, then the cross-correlation at lag (lead) $k$ is defined as follows:

$$
\rho\left(y_{t+k}, x_{t}\right)=\frac{T \sum_{t=k-1}^{T}\left(y_{t+k}-m_{y}\right)\left(x_{t}-m_{x}\right)}{(T+k) \sqrt{\sum_{t=k}^{T}\left(y_{t+k}-m_{y}\right)^{2} \sqrt{\sum_{t=k}^{T}\left(x_{t}-m_{x}\right)^{2}}}}
$$

where $\rho$ is the correlation coefficient and $m_{x}$ and $m_{y}$ are the means of corresponding series. The series can be related in three possible ways: (i) $y_{t}$ can lead $x_{t}\left(\rho\left(y_{t-k}, x_{t}\right) \neq 0\right)$, (ii) $y_{t}$ can lag $x_{t}\left(\rho\left(y_{t+k}, x_{t}\right) \neq 0\right)$, (iii) series can be contemporaneously related $\left(\rho\left(y_{t}, x_{t}\right) \neq 0\right)$.

\section{CROSS CORRElation ANALYSIS}

We run four cross correlations for each country. The series of cyclical component of REER was shifted up to four lags and leads relative to the cycle in respective macroeconomic variable. The obtained correlation coefficients are presented in Fig. 1. We report cross correlations for all countries as well as the average value. In accordance with [6] we define the exchange rate as procyclical, acyclical, or countercyclical depending on whether the respective correlation coefficient is positive, zero, or negative. If the coefficient in absolute value is higher than 0.26 we consider this as a strong correlation, values between 0.13 and 0.26 denote weak correlation and coefficients lower than 0.13 imply no correlation.

(a) $\mathrm{GDP}_{t}-\mathrm{REER}_{t+k}$

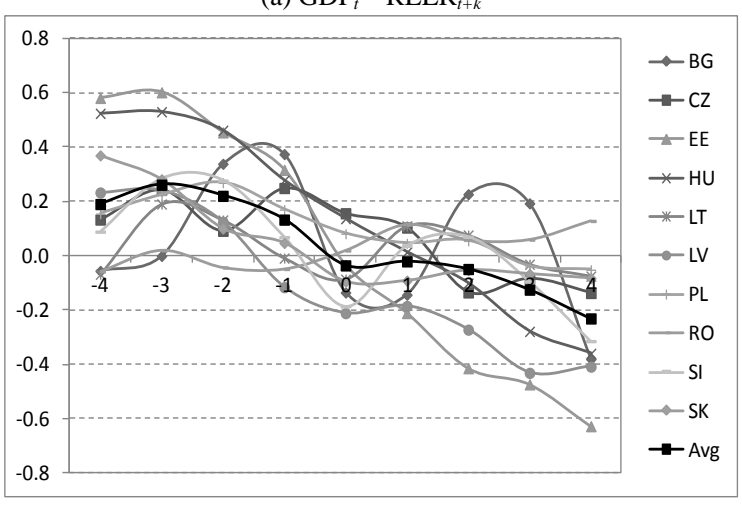

(b) Long-term interest rate $_{t}-\mathrm{REER}_{t+k}$

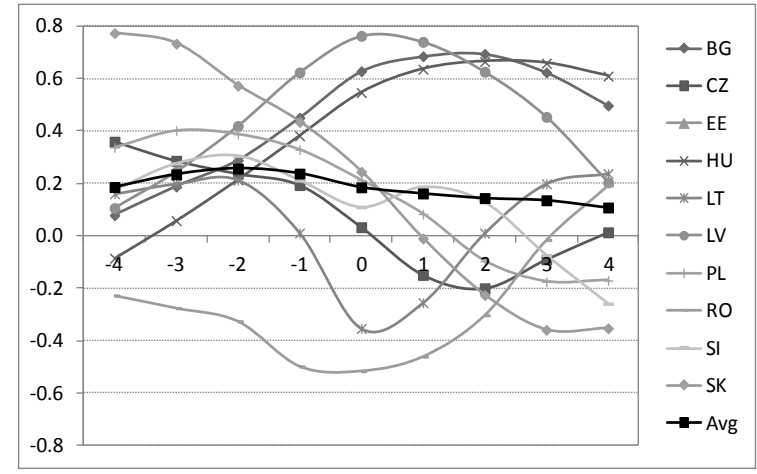

(c) Money supply se $_{t}$ RER $_{t+k}$

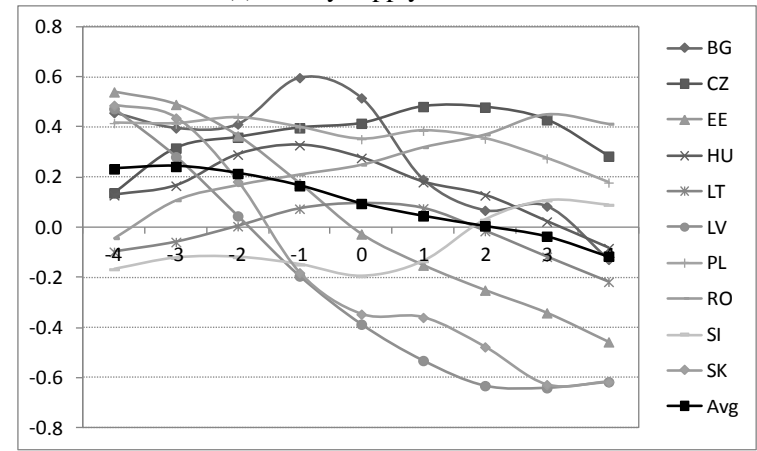

(d) Trade balance ${ }_{t}-$ REER $_{t+k}$

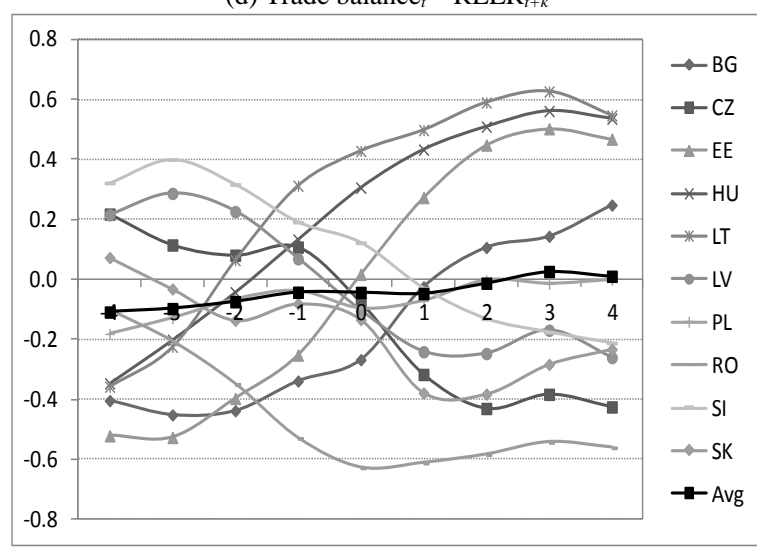

Note: Lags and leads refer to time shift of time series of exchange rate

Fig. 1. Cross correlation between macroeconomic fundamentals and exchange rates.

The cross correlation functions depicted in Fig. 1 often 
resemble the letter $\mathrm{S}$ or reverse letter $\mathrm{S}$. The $\mathrm{S}$-curve occurs if correlation coefficients are positive only between the current value of macroeconomic fundamental and future values of REER and the cross correlation is negative between the current value of fundamental and past values of REER. In terms of cyclicality, REER is procyclical if it lags the fundamental but countercyclical if it leads the fundamental. The reverse-S-curve describes inverse conditions and shows the procyclicality of leading REER and countercyclicality of lagging REER.

The results of cross correlations between GDP and REER are the most consistent across the countries among all macroeconomic variables. Almost all countries follow a reverse-S-curve pattern. The most notable exception is Romania which seems to be an outlier also in correlations with other fundamentals. REER leads GDP mostly by three quarters and correlation coefficients range from 0.6 in $\mathrm{EE}$ to 0.0 in BG. Slightly lower but negative coefficients were obtained for lagged REER.

The correlation between long-term interest rate and REER was done only for nine countries since the yields of 10-year government bonds are not available for EE. We obtained a very diverse set of correlation functions. There is conformity neither on direction of cyclicality nor on time shift with highest correlation coefficients. However, it is interesting that one can identify three groups, each consisted of three countries, that exhibit similar correlation pattern. The most homogeneous is the group containing BG, HU and LV. These countries show significant procyclical relationship between REER and long-term interest rate with strongest correlation at a lead of 1-2 quarters (i.e. REER lags the interest rate).

Substantial differences can be also found in results of correlation between REER and money supply measured as the M3 monetary aggregate. The only aspect common for almost all countries is that correlation rises with increasing time shift of REER any of the directions. Coefficients in many countries can be considered as a strong correlation (e.g. -0.6407 for $\mathrm{LV},-0.6281$ for $\mathrm{SK}$ or 0.5403 for $\mathrm{EE})$. The average correlation coefficients indicate a procyclicality of REER at lags and weak countercyclicality at leads.

The most controversial results were revealed in correlation between REER and trade balance indicator. Whereas four countries (BG, EE, HU, LT) exhibit an S-curve pattern, five countries (CZ, LV, PL, SI, SK) show a reverse-S-curve. Similarly with the case of money supply, correlation peaks at both ends of the time shift range pointing to a strong relationship between trade balance and leading/lagging REER. This is opposed to extremely flat curve of average correlation coefficient, which is, however, a logical outcome of arithmetical averaging in conditions of remarkable differences among countries.

Since the graphs in Fig. 1 depict only a simple arithmetical average of correlation coefficients, it is impossible to use the simple average to draw any conclusion on the lead/lag at which the correlation is the most intensive. Hence, Table I reports the highest average of absolute values of national correlation coefficients and respective lead/lag at which this mean value peaks. Obviously, coefficients in absolute values cannot be used for examination of procyclicality and countercyclicality of REER but only for assessment of the correlation's strength.

TABLE I: HigheSt AVERAGE OF ABSOLUTE VALUES OF CORRELATION COEFFICIENTS WITH RESPECTIVE TIME SHIFT

\begin{tabular}{cccccccc}
\hline \hline \multicolumn{2}{c}{ GDP } & \multicolumn{2}{c}{ Long-term IR } & \multicolumn{2}{c}{ Money supply } & \multicolumn{2}{c}{ Trade balance } \\
avrg. & shift & avrg. & shift & avrg. & shift & avrg. & shift \\
\hline 0.262 & -3 & 0.341 & 0 & 0.310 & 3 & 0.350 & 4 \\
\hline \hline
\end{tabular}

The countries' REER seem to be in average mostly correlated with trade balance and long-term interest rates and, to a lesser extent, with money supply. The weakest average correlation was found for GDP. Except of long-term interest rate the strongest correlation between REER and fundamentals is demonstrated at leads or lags greater than two quarters. The role of time shift in cross correlation is further documented in Table II. It presents a frequency of highest correlation coefficient in absolute values as of respective time shift of REER.

\begin{tabular}{ccccc}
\multicolumn{5}{c}{ TABLE II: LEADS AND LAGS WITH HIGHEST CORRELATION COEFFICIENT } \\
\hline \hline lead/lag & GDP & $\begin{array}{c}\text { Long-term } \\
\text { IR }\end{array}$ & $\begin{array}{c}\text { Money } \\
\text { supply }\end{array}$ & $\begin{array}{c}\text { Trade } \\
\text { balance }\end{array}$ \\
\hline-4 & 1 & 2 & 1 & 1 \\
-3 & 4 & 1 & 0 & 3 \\
-2 & 0 & 1 & 1 & 0 \\
-1 & 1 & 0 & 2 & 0 \\
0 & 0 & 3 & 1 & 1 \\
1 & 0 & 0 & 1 & 0 \\
2 & 0 & 1 & 0 & 2 \\
3 & 1 & 1 & 3 & 3 \\
4 & 3 & 0 & 1 & 0 \\
\hline \hline
\end{tabular}

In the final part of the discussion on relationship between REER and macroeconomic fundamentals we provide a list of fundamentals with highest average correlation coefficient in absolute value in all countries. In other words, Table III shows which macroeconomic fundamental is the most correlated with REER in each country. Whereas REER has the strongest relation with GDO only in EE, money supply is the most correlated fundamental in two countries, trade balance in three countries and long-term interest rate in four countries. This is completely in accordance with data presented in Table I.

TABLE III: FUNDAMENTALS MOST CORRELATED WITH REER

\begin{tabular}{|c|c|c|c|c|}
\hline BG & $\mathrm{CZ}$ & $\mathrm{EE}$ & LV & LT \\
\hline $\begin{array}{l}\text { Long- } \\
\text { term IR }\end{array}$ & $\begin{array}{l}\text { Money } \\
\text { supply }\end{array}$ & GDP & $\begin{array}{l}\text { Long- } \\
\text { term IR }\end{array}$ & $\begin{array}{c}\text { Trade } \\
\text { balance }\end{array}$ \\
\hline $\mathrm{HU}$ & PL & RO & SI & SK \\
\hline $\begin{array}{l}\text { Long- } \\
\text { term IR }\end{array}$ & $\begin{array}{l}\text { Money } \\
\text { supply }\end{array}$ & $\begin{array}{c}\text { Trade } \\
\text { balance }\end{array}$ & $\begin{array}{c}\text { Trade } \\
\text { balance }\end{array}$ & $\begin{array}{l}\text { Long- } \\
\text { term IR }\end{array}$ \\
\hline
\end{tabular}

\section{EFFECT OF COUNTRY'S OPENNESS}

The role and functions of exchange rates in economy depend on level of the country's openness. Theoretically, the more open economy the larger room for exchange rates to affect individual economic entities and economy as a whole. Therefore, we expect higher correlation between REER and macroeconomic fundamentals in more open countries.

Hence, we put the obtained correlation coefficients into relation with indicator of the country's openness which is calculated as follows: 


$$
\text { open }=\frac{|e x|+|i m|}{y}
$$

where ex denotes volume of exports, im is volume of imports and $y$ denotes GDP. In this formula, the higher the openness indicator open the more open the economy is. For the purpose of further analysis we computed the average value of the open indicator over the sample period. All national indicators are reported in Table IV.

TABLE IV: AVERAGE VALUES OF THE OPENNESS INDICATOR

\begin{tabular}{ccccc}
\hline \hline BG & CZ & EE & LV & LT \\
\hline 1.1712 & 1.1986 & 1.5181 & 1.0026 & 1.1507 \\
\hline HU & PL & RO & SI & SK \\
\hline 1.3806 & 0.6827 & 0.7464 & 1.1735 & 1.4806 \\
\hline \hline
\end{tabular}

(a) GDP - REER

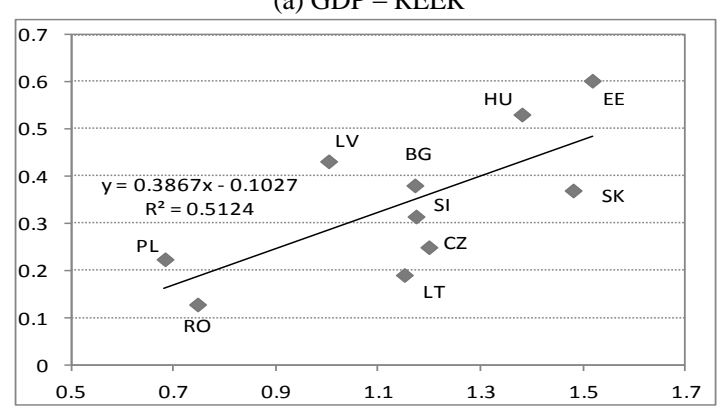

(b) Long-term interest rate-REER

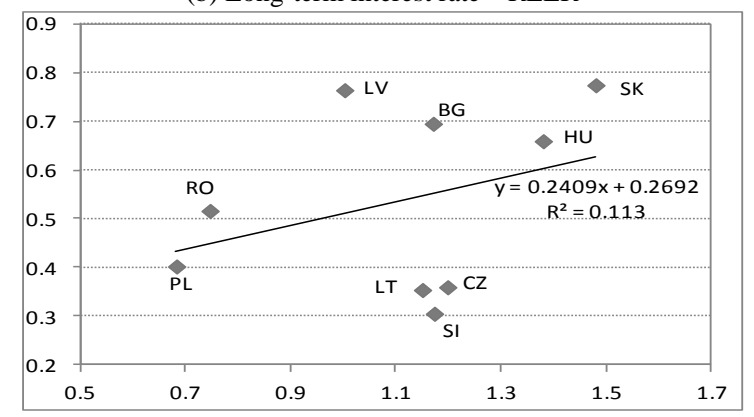

(c) Money Supply - REER

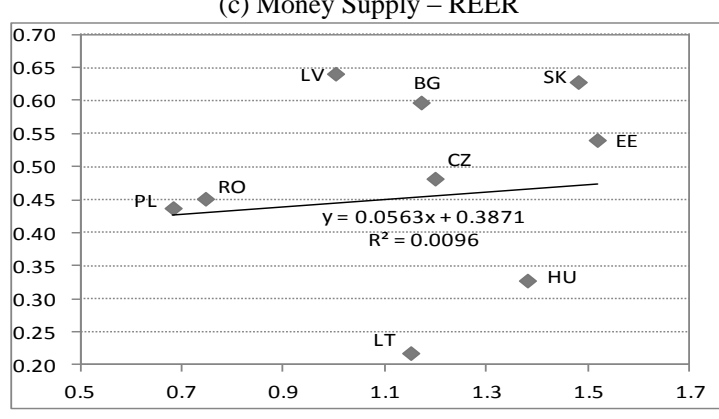

(d) Trade Balance - REER

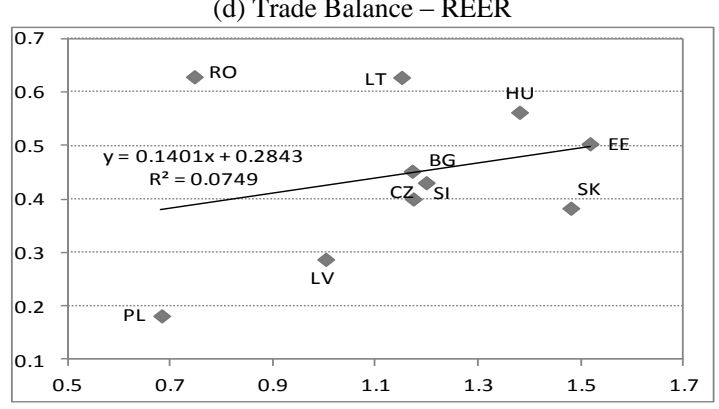

Note: The absolute value of correlation coefficient is on horizontal axis and the openness indicator on vertical axis.

Fig. 2. Regressions between correlation coefficient and openness.
The Fig. 2 portrays scatter plots with simple regressions between the absolute value of correlation coefficient and level of openness. We use the maximum cross correlation coefficient obtained in the interval of $(-4,4)$ lags.

It is evident from the graphs that our expectations about the effect of the country's openness are not fully confirmed by the actual results. On one hand, all regression coefficients are positive and indicate a positive impact of openness on the strength of correlation. On the other hand, however, estimated regressions show that the relationship between openness and correlation is rather weak.

Virtually no relation exists if correlations are done with money supply and trade balance, which is documented by the coefficients of determination $\mathrm{R}^{2}$ very close to zero. The strongest relationship was found between country's openness and GDP-REER correlation. The coefficient of determination above 0.5 provides solid evidence that the GDP-REER correlation is more pronounced in more open countries.

\section{CONCLUSION}

The aim of the present paper was to identify a nature of relationship between exchange rates and selected macroeconomic fundamentals in ten countries from Central and Eastern Europe. By application of cross correlation on cyclical components of time series of REER and four selected macroeconomic fundamental we found remarkable differences in the REER-fundamentals relationship across the countries. This prevents us from drawing universal conclusions applicable to any of the Central and Eastern European countries.

Nevertheless, we can conclude that the strongest correlation in average was revealed in pairs of trade balance REER and long-term interest rate - REER. Hence, we can point out that these two macroeconomic fundamentals are mostly related to REER in analyzed countries. As regards to cyclicality of REER, results differ remarkably across the countries and fundamentals. However, if we accept a considerable cross-country generalization, we can conclude that REER indices seem to procyclical if they lead and countercyclical if they lag GDP. This is illustrated by a reverse-S-curve exhibited by all countries. Moreover, REER usually has procyclical properties if it leads long-term interest rate and money supply.

We further related the cross correlations to indicator of country's openness. Except of GDP we did not reveal firm evidence that the openness has impact on magnitude of cross correlation.

The conducted analysis was motivated by monetary exchange rate determination models that relate macroeconomic fundamentals to exchange rates and assume relevance of the fundamental in forecasting of exchange rate development. Based on empirical analysis in this paper we come to the conclusion that such a relationship in Central and Eastern European countries is rather weak and often contradictory. Using macroeconomic fundamentals to predict behavior and development of exchange rate in this region remains, therefore, questionable. 


\section{REFERENCES}

[1] Y. W. Cheung, M. D. Chinn, and A. G. Pascual, "Empirical exchange rate models of nineties: Are any fit to survive?" Journal of International Money and Finance, vol. 24, pp. 1150-1175, November 2005.

[2] M. Dal Bianco, M. Camacho, and G. P. Quiros, "Short-run forecasting of the euro-dollar exchange rate with economic fundamentals," Journal of International Money and Finance, vol. 31, pp. 377-396, March 2012.

[3] P. D. Grauwe and M. Grimaldi, "Exchange rate puzzles: A tale of switching attractors," European Economic Review, vol. 50, pp. 1-33, January 2006.

[4] M. Obstfeld and K. S. Rogoff, "The six major puzzles in international economics: Is there a common cause?" in NBER Macroeconomics Annual 2000, B. Bernanke and K. S. Rogoff, Ed. Cambridge: MIT Press, 2001, pp. 339-412.

[5] L. Dedola, and S. Leluc, "Why is the business cycle behaviour of fundamentals alike across exchange rate regimes," International Journal of Finance and Economics, vol. 6, pp. 401-419, October 2001.
[6] J. Rand and F. Tarp, "Business cycles in developing countries: Are they different?" World Development, vol. 30, pp. 2071-2088, December 2002 .

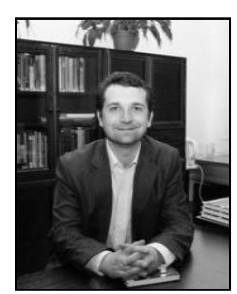

Daniel Stavárek is the Vice Dean of Foreign Affairs, Head of Department of Finance and Associate Professor of Finance at the School of Business Administration, Silesian University, Czech Republic. His research interests are in international finance, foreign exchange markets and exchange rates, banking and international financial and monetary institutions Prof. Stavárek published extensively in scientific peer-reviewed journals such as Emerging Markets Finance and Trade, Applied Economics Letters or Eastern European Economics. He is also author and co-author of monographs and book chapters. He is a member of Czech Economic Society, International Economic Society and its Advisory Board and Society for the Study of Emerging Markets. He serves as a co-editor and member of editorial boards of several scientific journals and member of program committees of international conferences. 